\title{
ANÁLISE DAS PESQUISAS SOBRE A POLÍTICA DE FORMAÇÃO INICIAL DE PROFESSORES NO PERÍODO DE 2002-2016
}

\author{
Carina Nogueira de Jesus ${ }^{1}$, Fábio Perboni ${ }^{2}$ \\ ${ }^{1}$ Graduada em Pedagogia pela Universidade Federal de Mato Grosso do Sul - UFMS. Mestranda do Programa de Pós-Graduação em Educação pela \\ Universidade Federal da Grande Dourados - UFGD, Dourados, MS. E-mail: caarinaanogueira@hotmail.com \\ ${ }^{2}$ Doutor em Educação pela Universidade Estadual Paulista (UNESP), campus de Presidente Prudente. Professor da Faculdade de Educação e do \\ Programa de Pós-Graduação em Educação da Universidade Federal da Grande Dourados - UFGD, Dourados, MS.
}

\section{RESUMO}

Este trabalho compõe resultados parciais de dissertação de Mestrado em andamento intitulada " $A$ implementação da Política Nacional de Formação de Professores na UFGD: análise sobre os cursos de Geografia e História", desenvolvida junto ao Programa de Pós-Graduação em Educação da Universidade Federal da Grande Dourados (UFGD). Refere-se a um levantamento da produção acadêmico-científica sobre Políticas de Formação Inicial de Professores no Brasil no período de 2002 a 2016 . Quanto à metodologia, foi realizado o levantamento e análise de títulos, resumos e eventualmente, de introduções de teses e dissertações disponíveis na Biblioteca Digital de Teses e Dissertações (BDTD) e no Banco de Teses e Dissertações da Coordenadoria de Aperfeiçoamento de Pessoal de Nível Superior (CAPES). Ademais, foram utilizados os descritores: "Políticas de Formação de Professores", "Políticas de Formação Docente" e "Políticas de Formação Inicial". A partir dos 628 resultados encontrados, foram selecionadas 40 produções correspondentes ao recorte deste mapeamento, sendo 12 Teses e 28 Dissertações. Posteriormente, esses trabalhos foram divididos em 4 agrupamentos para a realização da análise. Os dados das pesquisas evidenciam que as políticas de formação inicial, embora tragam contribuições para o processo formativo, ainda estão pautadas em ações pontuais de cunho emergencial, criadas para sanar determinados problemas sem a devida articulação entre as propostas elaboradas e os profissionais encarregados de sua implementação.

Palavras-chave: Políticas educacionais; Formação de professores; Licenciaturas.

\section{ANALYSIS OF RESEARCH ON INITIAL TRAINING POLICY FOR TEACHERS IN THE PERIOD 2002-2016}

\section{ABSTRACT}

This paper composes partial results of Master's dissertation in progress entitled "The implementation of the National Policy of Teacher Training in the UFGD: analysis on the courses of Geography and History", developed with the Graduate Program in Education of the Federal University of Grande Dourados (UFGD). It refers to a survey of the academic-scientific production on Policies of Initial Teacher Training in Brazil from 2002 to 2016. As for the methodology, a survey and analysis of titles, abstracts and, possibly, introductions of theses and dissertations available at the Digital Library of Theses and Dissertations (BDTD) and the Bank of Thesis and Dissertations of the Coordination of Improvement of Higher Education Personnel (CAPES). In addition, the descriptors: "Teacher Training Policies", "Teacher Training Policies" and "Initial Training Policies" were used. From the 628 results found, 40 productions corresponding to the cut of this mapping were selected, being 12 Theses and 28 Dissertations. Subsequently, these works were divided into 4 groups for the analysis. The research data show that initial training policies, while contributing to the training process, are still based on specific emergency actions, designed to address certain problems without the proper articulation between the proposals made and the professionals in charge of their implementation.
\end{abstract}

Keywords: Educational policies; Teacher Training; Degrees. 


\section{INTRODUÇÃO}

As políticas públicas brasileiras foram influenciadas pelo contexto de reforma do Estado, marcado por transformações em diversos âmbitos da sociedade, pela presença do neoliberalismo na economia, reestruturação produtiva e desenvolvimento do processo de globalização. Esses reordenamentos na estrutura do Estado fizeram com que houvesse um redimensionamento de suas funções, inclusive para o campo educacional.

Entende-se que a formação de professores para a educação básica tem se convertido, desde a década de 1990, em um dos focos das discussões em torno da política educacional brasileira, sob a influência de organismos internacionais como a Comissão Econômica para a América Latina e Caribe (CEPAL) e o Banco Mundial. Defendia-se que a formação de professores poderia corroborar para a elevação da qualidade da educação, com vistas à promoção do crescimento econômico e preparação para o mercado de trabalho, por meio de mudanças no processo de ensino.

Nessa perspectiva, Mindal e Guérios (2013) apontam que as questões relacionadas com a formação de professores são discutidas há muito tempo, abarcando novas análises e temáticas, contudo, segundo as autoras, "discute-se muito, mas na prática parece pouco o reflexo no avanço qualitativo da formação" (MINDAL; GUÉRIOS, 2013, p. 22).

Ao rememorar a trajetória da formação inicial desses profissionais, Gatti (2010) pontua que no Brasil foi proposta formação de professores para o ensino das primeiras letras a partir da criação das Escolas Normais, no final do século XIX. Em meados do século XX emergiu uma preocupação com a formação docente para o ensino "secundário"1 que, até o momento, era exercido por profissionais liberais ou autodidatas. No final dos anos de 1930, a partir da formação de bacharéis nas poucas universidades então existentes, acrescenta-se um ano com disciplinas da área de educação para a obtenção da licenciatura, está dirigida à formação de docentes para 0 "ensino secundário"

\footnotetext{
1 Atualmente, é denominado como Anos Finais do Ensino Fundamental (60 ao 9o ano).
}

\begin{abstract}
(formação que veio a denominar-se popularmente "3 +1 "). Esse modelo veio se aplicar também ao curso de Pedagogia, regulamentado em 1939, destinado a formar bacharéis especialistas em educação complementarmente, professores para as Escolas Normais em nível médio (GATTI, 2010, p. 1356).
\end{abstract}

Esse modelo formativo previa que a formação de bacharel tivesse uma complementaridade de um ano para a realização de disciplinas de cunho pedagógico, com vistas a possibilitar o formado para atuar como professor, lecionando algumas disciplinas para o ensino secundário, em Escolas Normais de nível médio, mesmo com a formação inicial de bacharel.

Após esse período, percebem-se novas significações para o campo da formação de professores, uma vez que as políticas educacionais instituíram exigências para os cursos de formação inicial de professores. A Lei de Diretrizes e Bases (LDB), promulgada no ano de 1996, passou a exigir a formação em cursos de licenciatura, para a atuação de docentes na educação básica, mesmo com a admissão de formação mínima em nível médio, na modalidade Normal.

No Brasil, a formação
inicial do professor
deveria realizar-se em
cursos de primeira
licenciatura, em nível
superior. Nesse caso, o
diploma de licenciado é
condição sine qua non
para o postulante
concorrer a uma vaga,
mediante concurso de
provas e títulos, a fim de
exercer a profissão de
professor e a atuar na
educação básica pública.
(BRZEZINSKI, 2014, p.
1247).

Nesse sentido, compreende-se a licenciatura como cursos que formam professores para os níveis e modalidades da educação básica (Educação Infantil, Ensino 
Fundamental, Ensino Médio, Ensino Profissionalizante, Educação de Jovens e Adultos e Educação Especial). Além disso, atualmente, as Diretrizes Curriculares Nacionais para a Formação Inicial e Continuada em Nível Superior de Profissionais do Magistério para a Educação Básica ( $D C N$ 's), indicam que a formação inicial é traduzida no exercício do magistério em etapas e modalidades da educação, por meio da articulação entre teoria e prática e um currículo com especificidades de conteúdos da área de conhecimento, seus fundamentos e metodologias, bem como conteúdos relacionados aos fundamentos da educação, políticas públicas e gestão da educação, prática e metodologia de ensino, entre outros (BRASIL, 2015).

Segundo Gatti (2010, 1359), a questão institucionalização da formação e os currículos para a formação inicial, tem sido alvo de debates há algum tempo, pois existem diversos fatores que corroboram para tal: "as políticas educacionais postas em ação, o financiamento da educação básica, [...] as formas de estrutura e gestão das escolas, formação dos gestores, as condições sociais e de escolarização de pais e mães de alunos das camadas populacionais menos favorecidas (os 'sem voz')". Ademais, influem nos debates, a condição do professorado, no que concerne a sua formação inicial e continuada e condições de carreira e trabalho na escola.

Após a LDB, nota-se que os cursos de licenciatura tiveram uma forte expansão graças à criação de novas instituições de Ensino Superior e pela institucionalização da educação superior à distância, promovendo a oferta de cursos para a formação inicial e continuada de professores (ROMANOWSKI, 2011). Para mais, um arcabouço legal passou a emergir no sentido de se intentar uma maior organicidade quanto à formação de professores. Assim, uma série de regulamentações e reorientações foram emitidas pelo Conselho Nacional de Educação (CNE), a começar pelo ano de 2002, com a instituição das Diretrizes Curriculares Nacionais para a Formação de Professores da Educação Básica, sob forma de Pareceres e Resoluções, em que estabelece princípios orientadores para a formação de professores, tanto inicial como continuada.

Entretanto, para Gatti (2010) as licenciaturas dos professores especialistas ainda apresentavam a prevalência de formação com foco em uma área disciplinar específica, sobrepondo a formação pedagógica.

\begin{abstract}
Adentramos o século XXI em uma condição de formação de professores nas áreas disciplinares em que, mesmo com as orientações mais integradoras quanto à relação "formação disciplinar/formação para a docência", na prática ainda se verifica a prevalência do modelo consagrado no início do século XX para essas licenciaturas (GATTI, 2010, p. 1357).
\end{abstract}

Autores como Gatti, Barreto e André (2011) e Diniz-Pereira (2016) concordam que nos cursos de licenciatura, têm ocorrido o predomínio de uma formação acadêmica de caráter abstrato e genérico, insuficiente para a formação integral de um profissional da educação. As normativas nacionais conduzem para a existência de um espaço formativo destinado à recorrência de práticas docentes que aliam teoria e prática, contudo, percebe-se que tais orientações não estão se concretizando em diversas instituições formadoras.

Destaca-se, conforme Brzezinski (2014), que as ações dos governos nas últimas décadas posteriores à redemocratização do Estado brasileiro, ao definir e desenvolver as políticas de formação de profissionais da educação tem sido, predominantemente, pautadas por práticas de políticas pontuais e emergenciais, "por meio de planos e programas dispersos, marcados pela inorganicidade e desarticulação do próprio Ministério da Educação (MEC)" (BRZEZINSKI, 2014, p. 1243). Em suma, tem-se desconsiderado a importância de um controle social sistemático, de modo que não há uma política pública global que estabeleça relação entre qualidade dos processos formativos e condições de trabalho e carreira.

Destarte, tem-se como objetivo deste artigo, apresentar um mapeamento da produção acadêmico-científica sobre Políticas de Formação de Professores para a Educação Básica, visando à formação inicial desses profissionais. Desse modo, este levantamento é parte dos resultados iniciais de uma dissertação em andamento no Programa de Pós-Graduação em Educação da Universidade Federal da Grande Dourados (PPGEdu/UFGD). A pesquisa de Mestrado 
objetiva analisar a implementação da Política Nacional de Formação de Professores para educação básica, com ênfase para a Resolução $n$. 02/2015, nos cursos de Geografia e História da UFGD.

\section{MÉTODOS}

Diante ao exposto, para que o objetivo da pesquisa seja alcançado, recorre-se à abordagem qualitativa uma vez que a partir de suas características, é possível assumir vários métodos de "investigação para o estudo de um fenômeno situado no local em que ocorre, e enfim, procurando tanto encontrar o sentido desse fenômeno quanto interpretar os significados que as pessoas dão a eles" (CHIZZOTTI, 2003, p. 222). Assim, há uma partilha entre pessoas, fatos e locais que constituem o objeto da pesquisa com o intuito de extrair significados que somente são perceptíveis a uma atenção mais zelosa.

Para este texto, realizou-se o levantamento bibliográfico com base no período de 2002 a 2016 em dois bancos de dados online: a Biblioteca Brasileira de Teses e Dissertações (BDTD) e o banco de Teses e Dissertações da CAPES.

O motivo de escolha deste período é justificado mediante a instituição das DCN's, pela Resolução 01/2002 que passou a orientar a organização curricular dos cursos de licenciatura. Ademais, o ano de 2016 compreende o período de instituição da Resolução n. 02/2015, referente às $D C N$ 's, e prevê a reformulação de diversos pontos nos cursos de formação inicial e a regulamentação da Política Nacional de Formação dos Profissionais para a Educação Básica, que tem por finalidade organizar e efetivar a formação de profissionais da educação básica, em regime de colaboração entre os municípios, os estados, o Distrito Federal e a União, em consonância com o Plano Nacional de Educação (PNE).

Para o levantamento bibliográfico, os descritores utilizados foram: "Políticas de Formação de Professores", "Políticas de Formação Docente" e "Políticas de Formação Inicial". Com o intuito de apurar a seleção das produções, optou-se pela utilização de aspas como um dos recursos para delimitação dos resultados, devido à amplitude de pesquisas que abarcavam questões não relevantes para este recorte.

Nesse sentido, com o primeiro descritor, realizou-se a seguinte variação: "Políticas de
Formação de Professores" e "Políticas" de Formação de Professores, o que resultou em diferentes resultados em termos de quantidade. Além de recorrer à utilização de aspas, usou-se também o filtro de "recorte temporal".

Com este processo de filtragem, foram encontradas 206 produções no Banco de Teses da CAPES e 422 produções na BDTD, totalizando 628 trabalhos. Posteriormente, realizou-se a análise dos títulos, dos resumos e, eventualmente, das introduções dos trabalhos, pois alguns não possuíam resumos em concordância com a proposta de pesquisa apresentada.

Sendo assim, dentre este montante de 628 produções, foram excluídas aquelas que tratavam sobre o curso de Pedagogia ${ }^{2}$, políticas e programas para a Educação Infantil, políticas de alfabetização, formação estética do professor, formação política do professor, estágio supervisionado em cursos de graduação com habilitação bacharelado e/ou tecnológico, política para a formação de professores na perspectiva da inclusão, tutoria na Educação a Distância (EaD) e formação de professores para a educação técnica/profissional. Além dessas temáticas, alguns trabalhos, pertinentes ou não ao recorte desta pesquisa, repetiram-se em até três vezes no mesmo banco de dados, bem como a recorrência em ambos os bancos digitais de dados.

Após esta triagem, foram selecionados 107 teses e dissertações, divididas em 3 (três) grupos temáticos: políticas de formação inicial, políticas de formação continuada, políticas de formação e trabalho docente. Ademais, o grupo que será enfatizado neste texto, trata das políticas de formação inicial, mediante as análises de políticas, programas e ações implementadas pelas instâncias e órgãos do governo. Há nesse caso, uma totalidade de 40 trabalhos selecionados, sendo 12 teses e 28 dissertações.

Outrossim, este texto organiza-se de modo a apresentar o mapeamento realizado enfatizando, inicialmente, aspectos como a distribuição regional, por Universidade e Programas de Pós-Graduação das produções selecionadas. Para a análise dos dados quanto à temática, divide-se as pesquisas em 4 (quatro) agrupamentos: Políticas, ações e programas para a formação inicial de professores em exercício;

\footnotetext{
${ }^{2} \mathrm{O}$ curso de Pedagogia não se insere nesta pesquisa por apresentar uma organização curricular complexa desde sua institucionalização.
} 
Programa Institucional de Bolsas de Iniciação à Docência (PIBID); Formação Inicial e Políticas curriculares e Macro e Micro Implementação de políticas, ações e programas.

\section{RESULTADOS}

O recorte dado a este mapeamento referente às políticas de formação inicial reúne produções de caráter relevante para o trabalho de Dissertação de Mestrado em andamento, pertencentes a diferentes regiões do Brasil. Dentre as 40 pesquisas, a maior parte está concentrada na Região Sudeste, com 14 trabalhos; 10 pesquisas pertencem a Programas de Pós-Graduação (PPG) da Região Nordeste; 10 teses e dissertações foram selecionadas na Região Sul e 06 produções na Região CentroOeste. A Região Norte não apresentou recorrência de dados.

Gráfico 1. Distribuição regional das produções acadêmico-científicas - Período 2002 a 2016

\section{Gráfico 1}

$\because$ SUDESTE $\square$ SUL $\square$ NORDESTE $\square$ CENTRO-OESTE $\square$ NORTE

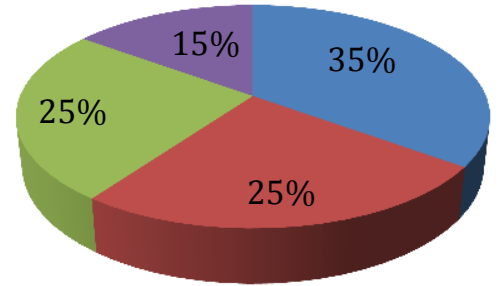

Fonte: Banco de Teses e Dissertações da CAPES; BDTD. Elaborado pelos autores, 2017.

Percebe-se uma incidência maior das pesquisas selecionadas em Programas de PósGraduação da Região Sudeste. Isto está atrelado ao fato de a região possuir o maior ${ }^{3}$ quantitativo de programas stricto sensu do país, seguido pela região Sul, Nordeste, Centro-Oeste e Norte, respectivamente. Nesse sentido, a região tem se constituído como lócus fértil para pesquisas, já que concentra o maior número de cursos de PósGraduação e também apresenta o maior número de matrículas em cursos de graduação presenciais (47,2\%) (SEMESP, 2015). Em contrapartida, a Região Norte se caracteriza pelo recente início de implementação de PPG's, considerando que o estado do Amapá foi o último a implantar um programa stricto sensu a nível nacional (TANJI, 2017).

A maioria das 40 pesquisas selecionadas estão vinculadas a Programas de Pós-Graduação em Educação de diversas Universidades Federais, Estaduais e Particulares, sendo um total de 32 produções. Dentre essas instituições de Ensino Superior, destacam-se aquelas que possuem 0

\footnotetext{
${ }^{3}$ Disponivel em:

<https://sucupira.capes.gov.br/sucupira/public/consultas/coleta/pr ograma/quantitativos/quantitativoRegiao.jsf>.
}

maior número de produções em Educação: Universidade Estadual de Campinas (UNICAMP), Universidade Estadual Paulista (UNESP), Universidade de São Paulo (USP), Universidade Federal de Santa Catarina (UFSC), Universidade do Oeste de Santa Catarina (UNOESC), Universidade do Vale do Rio dos Sinos (UNISINOS), Pontifícia Universidade Católica (PUC) em Goiás e Minas Gerais e Universidade de Brasília (UnB).

Outras 2 (duas) pesquisas pertencem ao Programa de Mestrado Profissional em Avaliação de Políticas Públicas da Universidade Federal do Ceará (UFC). Os Programas de Educação Escolar (UNESP), Educação em Ciências e Matemática (Universidade Federal de Goiás - UFG), Ciência e Matemática (Universidade Federal do Paraná UFPR), Educação Científica e Formação de Professores (Universidade Estadual do Sudoeste da Bahia - UESB), Educação, Arte E História Da Cultura (Mackenzie), Gestão de Políticas Públicas e Segurança Social (Universidade Federal do Recôncavo da Bahia - UFRB) apresentam uma produção cada.

Quanto à divisão anual da produção elencada, percebe-se que grande parte foi 
defendida nos anos de 2016 (8), 2014 (5), 2006 (5) e 2011 (4), os quais são períodos que abarcam a instituição de um arcabouço de políticas que configuram a Política Nacional de Formação de Professores, a saber: Resolução n. 01/2002, Resolução n. 02/2015, Decreto n. 6.755/2009, Plano Nacional de Formação de Professores da Educação Básica (Parfor), PIBID, entre outros, fazendo com que as investigações privilegiassem análises sobre diversos aspectos dessas políticas.

\section{DISCUSSÕES}

As pesquisas que versam sobre o campo da formação de professores têm crescido demasiadamente nos últimos anos. Embora as análises sobre as políticas de formação tenham se desenvolvido a largos passos, esse ainda não é um objeto de interesse das investigações do campo se comparada, proporcionalmente, a estudos que abordam sobre "as concepções, representações, saberes e práticas do professor" (ANDRÉ, 2010, p. 179), evidenciando suas experiências de formação com as práticas no ambiente da sala de aula.

Atualmente, a legislação educacional brasileira, indica que as licenciaturas são os cursos responsáveis pela formação dos professores para toda a educação básica, entretanto, dentre um universo de 2,1 milhões de professores no Brasil, cerca de 77,5\% possuem formação em nível superior. Destes, 46,9\% possuem diploma na área que lecionam no Ensino Fundamental e 54,9\% no Ensino Médio (BRASIL, 2016). Estas estatísticas revelam que grande parte dos docentes não possui formação para sua área de ensino, realidade que influi sobre a criação de políticas emergenciais e pontuais para tentar sanar tal situação.

Os trabalhos selecionados foram organizados em quatro agrupamentos a partir da análise de seus títulos, resumos e, eventualmente, de suas introduções, sendo categorizados mediante à totalidade de produção acerca de temáticas recorrentes entre os mesmos. Sendo assim, a análise dessas produções está pautada na divisão em agrupamentos que representam quantitativamente discussões voltadas à compreensão de: iniciativas para a formação inicial de professores em exercício; do Programa Institucional de Bolsas de Iniciação à Docência (PIBID); políticas curriculares para a formação inicial e políticas e programas em nível de macro e micro implementação para formação docente.
Nesse sentido, o agrupamento "Políticas, ações e programas para a formação inicial de professores em exercício", apresenta 07 produções que abordam, de modo geral, sobre as iniciativas legais criadas pelo MEC e pela CAPES para oferecer formação em nível superior àqueles professores que possuem somente formação em nível médio e que estão exercendo a profissão.

Dessa totalidade, 06 pesquisas tratam de programas específicos criados para oferecer formação em nível superior para os professores em exercício. Ao analisar as contribuições geradas pelo programa PROHACAP, em Rondônia, Borges (2011) identificou que embora o projeto fosse consistente, a sua execução passou por alguns percalços, como: ausência de registros sobre o planejamento pedagógico e avaliações do programa.

A tese de Lauande (2010) analisa o Programa Especial de Formação de Professores para a Educação Básica (PROEB), oferecido pela Universidade Federal do Maranhão (UFMA), no período de 1998 a 2002, operacionalizado pelo curso de Licenciatura em Matemática, no município de Vitória do Mearim/MA. Rocha (2006) e O'Reilly (2005) fazem uma análise sobre o Projeto Veredas, que é de iniciativa do estado de Minas Gerais para habilitar em nível superior os profissionais em exercício da rede estadual e municipal via EaD.

As dissertações de Ferreira (2004) e Viana (2011) analisam o programa Magister Ceará, tanto pela visão dos gestores como pela visão do professor que fez a formação, respectivamente. Pelos dados levantados, Viana (2011) constatou que $90 \%$ dos professores cursistas concluíram o curso, contribuindo para o aumento do índice de professores com formação em nível superior. Ferreira (2004) analisa as contradições na elaboração e implementação do programa e conclui que nem sempre os professores conseguem ter suas reivindicações atendidas devido aos conflitos políticos existentes no interior da formulação e implementação dessas políticas.

A tese de Bolson (2016) "As políticas de formação inicial de professores em exercício no Brasil" vai ao encontro das pesquisas citadas outrora, ao evidenciar que as políticas de formação de professores em exercício têm apresentado poucas inovações em sua constituição, haja vista a existência de uma característica pautada no aligeiramento de uma 
certificação em contrapartida a uma formação sólida para o exercício da profissão.

Estes cursos, apesar de ainda apresentarem uma organização curricular disciplinar que instrumentaliza o currículo, trouxeram repercussões para a inserção desses professores no mercado de trabalho e melhoria das práticas pedagógicas. Depreende-se que, mesmo com diversas fragilidades, esses programas contribuíram para a ampliação do universo sociocultural por meio da epistemologia da prática, ao passo em que a visão de mundo dos docentes foi mudada, influenciando em sua prática.

Além disto, muitos estudos têm se debruçado a analisar o Programa Institucional de Bolsas de Iniciação à Docência (PIBID), explicitando suas controvérsias e contribuições para o processo formativo dos futuros professores. Assim, foram elencadas 07 pesquisas que tratam a respeito do programa.

Destarte, durante 0 processo de formação inicial, o licenciando se depara com ações do Estado e do governo para a melhoria de aspectos nos cursos de licenciatura. Nesse sentido, visando valorizar esses cursos, o PIBID é uma parceria entre o MEC e a CAPES com vistas a melhorar a qualidade das ações acadêmicas na formação inicial de professores. O programa fora lançando em 2007 e obteve sucesso na aproximação entre o Ensino Superior e as escolas públicas, já que tem como objetivo formar professores atentos às múltiplas facetas do cotidiano escolar, com a interlocução entre pesquisa e investigação para a resolução de situações e inovação na educação (BRASIL, 2014).

De modo geral, essas produções estão voltadas à análise do PIBID, a partir de sua implementação em cursos de variadas áreas e universidades, investigando as dimensões no processo formativo de professores, como as produções de Fedechem (2013), Moura (2013), Brasil (2014), Oliveri (2014) e Gimenes (2016). Esses trabalhos evidenciam que o PIBID tem fomentado a melhoria da formação inicial, ainda que em meio a diversas contradições, problemas e conflitos. Isso se dá pelo motivo de o programa proporcionar a interação em Universidadeescola-formação, de modo a propiciar o contato com a realidade educacional e a reflexão sobre a docência e o contexto escolar.

Moura (2013) corrobora que, embora existam demasiadas contribuições para a formação inicial docente, as ações do PIBID ainda possuem um considerável distanciamento entre as demais ações dos cursos de formação. Outrossim, o autor pontua que seria desnecessário uma política como o PIBID se a formação de professores fosse assumida como um compromisso do Estado brasileiro, na visão de uma totalidade do fenômeno educativo.

Berkembrock (2016) e Silva (2016) recorrem à visão dos gestores e ex-pibidianos para afirmar que o programa tem apresentado atividades de caráter inovador e metodologias diferenciadas. O PIBID se caracteriza como uma política educacional rica em resultados práticos nas escolas. Entretanto é necessário que haja preparação dos atores que fazem parte da política para que ela seja implementada satisfatoriamente. Ambas as pesquisas afirmam que o PIBID é uma política de suma importância para os cursos de Licenciatura, pois apresenta aportes teórico-metodológicos que ressignificam os cursos de formação de professores.

Sobre o agrupamento "Formação Inicial e Políticas curriculares", as pesquisas identificadas se relacionam com a análise do papel do Estado e das Políticas Educacionais para a formação de professores em cursos de licenciatura, no âmbito das proposições e reformulações curriculares expressas pelo MEC, na forma das DCN's.

No que tange as propostas de reformulação de cursos de licenciatura, Cruz (2005), Ferreira da Silva (2008), Vedovatto (2010), Azevedo (2008) e Leal (2011) analisam a reformulação curricular dos cursos de Ciências Biológicas, Filosofia, Artes, em cursos da Universidade Estadual de Goiás e em duas universidades paulistas, respectivamente, e destacam os impactos e relações concebidas neste processo. Os autores evidenciam que as reformas nessas licenciaturas ocorrem sob diferentes níveis de legitimação da participação dos agentes, tendo como consequência, disputas de poder e dos modos de regulação, os quais influenciam nas variadas concepções de currículo no decorrer do processo de reforma.

Para Medina da Silva (2006) e Canan (2009), as reformas nas Diretrizes, ocorridas sob diversas tensões e limites, têm o objetivo de dar continuidade a tendência de flexibilização curricular, resultando na perda da autonomia das universidades quanto ao aspecto didáticopedagógico, identidade institucional e profissional dos docentes. Igualmente, mesmo com a proposição de diversas mudanças nas políticas curriculares estabelecidas pelo MEC, 
alguns cursos acabam não possuindo um perfil próprio, como revela a pesquisa de Mattiauda (2006), que investigou o curso de Letras do Centro Universitário de Várzea Grande (UNIVAG).

Gomes (2013) discute a respeito da implementação de licenciaturas nos Institutos Federais de Educação, Ciência e Tecnologia. A análise evidencia dificuldades na implementação de cursos com habilitação em Licenciatura nessa instituição em específico, o qual mesmo sendo um lócus voltado à oferta de Educação Profissional e Tecnológica percebe-se que não houve desvio de sua função, apenas uma reconfiguração de sua missão e objetivos (GUIRADO, 2017).

Duas pesquisas analisam a implementação do componente curricular de Prática Profissional em curso do CEFET/RN (SILVA, 2006) e os sentidos do Estágio Supervisionado em meio às demandas, antagonismos e disputas hegemônicas de significação em torno de projetos de sociedade, de educação e de currículo perante as políticas de formação (ARAÚJO, 2015).

Reitera-se que, embora as políticas de formação direcionadas às licenciaturas contribuam para o desenvolvimento profissional docente ao passo em que estipulam a necessidade de haver uma formação específica para exercer a profissão, todavia, elas são concebidas de forma verticalizada, sendo impostas pelo MEC, sem considerar as questões estruturais reais das instituições de ensino.

Ademais, o agrupamento "Macro e Micro Implementação de políticas, ações e programas" possui produções que fazem análises de Políticas, ações e programas empreendidas pelo MEC e CAPES bem como, pelos estados e Universidades que criam projetos em busca de incentivar a formação inicial de professores e possibilitar o contato com práticas pedagógicas inovadoras.

Muitos trabalhos analisam propostas institucionais de universidades para a formação inicial de professores, como é o caso de Souza (2011), Monteiro Oliveira (2016) e Carvalho (2014) que analisam projetos de formação inicial nos estados do Tocantins, Roraima e Piauí. Essas iniciativas se inserem num contexto em que não havia qualquer iniciativa de incentivo à docência por órgãos de fomento ligados ao MEC, fato que resulta na diversificação e aumento das possibilidades de formação de professores.

Em meio aos trabalhos selecionados, 04 pesquisas (SANTOS SILVA, 2014; BASTOS, 2015;
SUSIN, 2015; FREITAS, 2016) referem-se especificamente ao PARFOR, trazendo em suas análises questões relacionadas à sua implementação, pressupostos e desafios.

O Plano Nacional de Formação de Professores da Educação Básica (PARFOR) foi lançado pelo MEC no ano de 2009, com o intuito de ofertar cursos de formação inicial e continuada, nas modalidades presencial e a distância, por meio da UAB. Segundo Rodrigues (2016), o Plano oferece cursos de primeira licenciatura para os docentes que não possuem formação em nível superior; segunda licenciatura para professores em exercício há no mínimo três anos e que atuem em área diferente de sua formação; além de formação pedagógica para os docentes que são graduados, mas não em uma Licenciatura.

Pelos dados, entende-se que as políticas de formação de professores adotadas pelos governos nos últimos anos não estão atendendo às necessidades colocadas pelos profissionais da educação. Há a ausência de uma política integrada e articulada com os profissionais da educação.

De modo análogo, Oliveira (2006), Rodrigues (2016), Gondim de Oliveira (2016) e Silva Neto (2017) analisam os programas federais de formação de professores, abarcando os projetos educacionais existentes a partir do Manifesto dos Pioneiros, perpassando por análises do governo Fernando Henrique Cardoso (FHC) e Lula e, atualmente os programas implementados pela Capes. Os autores inferem que os projetos recentes de formação se caracterizam em ações fragmentadas, descontextualizadas e sob a ótica do capital e da lógica mercadológica. Embora os programas implementados pela Capes e MEC não deixem de tocar em pontos levantamentos por especialistas, eles se constituem como iniciativas pontuais e ineficientes se consideradas as reais necessidades educacionais do país.

As políticas de formação inicial via EaD são focos das pesquisas de Malachen (2007), Masson (2009) e Mandeli (2014). Os estudos analisam o movimento da formação de professores via $\mathrm{EaD}$ e sua vinculação com as reformas do Estado e da Educação. Os dados apontam que estas políticas coadunam com o ideário de reforma do Estado, e oferecem uma formação aligeirada e flexibilizada, já que são elaboradas para atender problemas 
emergenciais, inviabilizando a construção de políticas em longo prazo.

Em suma, as produções selecionadas referem-se às políticas de formação de professores em cursos de licenciatura propostas por órgãos vinculados ao MEC e abrangem pesquisas relacionadas ao papel do Estado e do Governo na implementação de ações para a valorização e incentivo da formação inicial docente em nível superior, exigida pela LDB e outros documentos que normatizam a educação brasileira.

Evidencia-se que a maioria das pesquisas analisam as políticas de formação inicial de professores como ações pontuais, criadas para sanar determinadas lacunas existentes no processo educativo. Dessa forma, essas políticas se constituem sob diversos problemas, contradições e impasses que as tornam ineficientes para atender a realidade educacional do país, haja vista que recorrentemente, não atendem as reais condições estruturais e humanas da educação básica.

\section{AGRADECIMENTOS}

Agradecemos à Coordenação de Aperfeiçoamento de Pessoal de Nível Superior (CAPES), pelo apoio financeiro na realização desta pesquisa em andamento.

Os autores declaram não haver qualquer potencial conflito de interesse que possa interferir na imparcialidade deste trabalho científico.

\section{REFERÊNCIAS}

ANDRÉ, M. E. D. A. Formação de professores: a constituição de um campo de estudos. Educação, Porto Alegre, PUC/ RS, v. 33, n.3, p. 174-181, set./dez. 2010.

ARAÚJO, K. C. L. C. O debate da política curricular para a formação de professores e os sentidos do estágio supervisionado (1996-2006): demandas, antagonismos e hegemonia. 2015. 235f. Tese (Doutorado em Educação) - Universidade Federal do Pernambuco, Recife, 2015. Disponível em:<http://www.bdtd.ufpe.br/bitstream/handle/ 123456789/15332/Ka\%cc\%81tia\%20Corr\%c3\%аa a\%2012\%2008\%202015\%20-

\%20vers\%c3\%a3o\%20final\%20impress\%c3\%a3o. pdf? sequence $=1$ \&isAllowed $=y>$. Acesso em: 29 dez. 2017.
AZEVEDO, I. A. M. As políticas educacionais e o processo de formação do professor nos cursos de licenciatura. 2008. 193f. Dissertação (Mestrado em Educação) - Universidade de Brasília, Brasília, 2008. Disponível em:< http://repositorio.unb.br/bitstream/10482/1660/ 1/Dissert_Ivana\%20Azevedo.pdf>. Acesso em:08 dez. 2017.

BASTOS, A. F. B. de O. Análise da implementação do Plano Nacional de Formação de Professores da Educação Básica em estados da região norte do Brasil. 2015. 208 f. Tese (doutorado) Universidade Estadual de Campinas, Faculdade de Educação, Campinas, SP. Disponível em: <http://www.bibliotecadigital.unicamp.br/docum ent $/$ ?code $=000953342 \&$ opt $=4>$. Acesso em: 29 dez. 2017.

BERKEMBROCK, I. T. M. O Programa Institucional de Bolsas De Iniciação À Docência (PIBID) como política de formação de professores: uma análise das percepções de formadores. 2016. $116 f$. Dissertação (Mestrado em Educação) Universidade do Oeste de Santa Catarina, Joaçaba, 2016. Disponível em:< https://sucupira.capes.gov.br/sucupira/public/co nsultas/coleta/trabalhoConclusao/viewTrabalhoC onclusao.jsf?popup=true\&id_trabalho $=3628300 \#$ >. Acesso em: 08 dez. 2017.

BOLSON, J. B. As políticas de formação inicial de professores em exercício no Brasil. 2016. 148f. Tese (Doutorado em Educação) - Universidade do Vale do Rio dos Sinos, São Leopoldo, RS, 2014. Disponível

em:<http://www.repositorio.jesuita.org.br/bitstr eam/handle/UNISINOS/6003/Jana\%c3\%adna\%20 Boniatti\%20Bolson_.pdf?sequence $=1$ \&isAllowed $=$ y>. Acesso em: 20 out. 2017.

BORGES, C. J. Professores leigos em Rondônia: entre sonhos e oportunidades, a formação e profissionalização docente - um estudo de caso o PROHACAP. 2011. 417 f. Tese (doutorado) Universidade Estadual Paulista, Faculdade de Ciências e Letras de Araraquara, 2011. Disponível em:<https://repositorio.unesp.br/bitstream/han dle/11449/101564/borges_cj_dr_arafcl.pdf?sequ ence=1\&isAllowed=y . Acesso em: 28 dez. 2017.

BRASIL, M. M. O PIBID no contexto das políticas de formação de professores de biologia e matemática na Universidade Estadual de Goiás. 
2014. 129 f. Dissertação (Mestrado em Educação em Ciências e Matemática) - Universidade Federal de Goiás, Goiânia, 2014. Disponível em:<https://repositorio.bc.ufg.br/tede/bitstream /tede/4831/5/Disserta\%c3\%a7\%c3\%a30\%20\%20Melca\%20Moura\%20Brasil\%20\%202014.pdf>. Acesso em: 28 dez. 2017.

BRASIL. Conselho Nacional de Educação. Resolução CNE/CP n. 02/2015, de 10 de julho de 2015. Define as Diretrizes Curriculares Nacionais para a formação inicial em nível superior (cursos de licenciatura, cursos de formação pedagógica para graduados e cursos de segunda licenciatura) e para a formação continuada. Diário Oficial da União, Brasília-DF, 02 jul. 2015. Disponível em:<http://pesquisa.in.gov.br/imprensa/jsp/visu aliza/index.jsp?data $=02 / 07 / 2015 \&$ jornal $=1 \&$ pagina $=8 \&$ totalArquivos=72>. Acesso em: 19 out. 2017.

BRASIL. Instituto Nacional de Estudos e Pesquisas Educacionais Anísio Teixeira. Censo Escolar Da Educação Básica 2016: Notas Estatísticas. Brasília: MEC/INEP, 2016. Disponível em:<http://download.inep.gov.br/educacao_basi ca/censo_escolar/notas_estatisticas/2017/notas estatisticas_censo_escolar_da_educacao_basica_ 2016.pdf>. Acesso em: 15 nov. 2017.

BRASIL. Ministério da Educação. Coordenação de Aperfeiçoamento de Pessoal de Nível Superior Capes. Relatório de Gestão da Diretoria de Formação de Professores da Educação Básica 2009-2014. DEB, 2014. Disponível em: http://www.capes.gov.br/images/stories/downlo ad/bolsas/20150818 DEB-relatorio-de-gestaovol-1-com-anexos.pdf. Acesso: 03 jan. 2018.

BRZEZINSKI, I. Sujeitos sociais coletivos e a política de formação inicial e continuada emergencial de professores: contradições Vs conciliações. Educação e Sociedade, Campinas, v. 35, n. 129, p. 1241-1259, out./dez., 2014. Disponível

em:<http://www.scielo.br/pdf/es/v35n129/01017330-es-35-129-01241.pdf>. Acesso em: 19 out. 2017.

CANAN, S. R. Diretrizes nacionais para a formação de professores da educação básica: tensões e limites entre o específico e o pedagógico na formação docente. 2009. 396f. Tese (Doutorado em Educação) Universidade do
Vale do Rio do Sinos, São Leopoldo, 2009. Disponível

em:<http://www.repositorio.jesuita.org.br/bitstr eam/handle/UNISINOS/2089/CananSilviaReginaE ducacao. pdf? sequence $=1$ \&isAllowed $=y>$. Acesso em: 29 dez. 2017.

CARVALHO, R. D. S. As ações de governamento empreendidas pela Universidade Estadual do Piauí na expansão da formação de professores. 2014. 112f. Dissertação (Mestrado em Educação) - Universidade do Vale do Rio dos Sinos, São Leopoldo, 2014. Disponível em:< http://www.repositorio.jesuita.org.br/bitstream/ handle/UNISINOS/4632/18d.pdf?sequence $=1 \&$ is Allowed=y>. Acesso em: 28 dez. 2017.

CHIZZOTTI, A. A pesquisa qualitativa em ciências humanas e sociais: evoluções e desafios. Revista Portuguesa de Educação, Braga-PT, v. 16, n. 2. p. 221-236, 2003. Disponível em:< http://www.redalyc.org/html/374/37416210/>. Acesso em: 20 out. 2017.

CRUZ, J. S. Reforma curricular do curso de licenciatura em Biologia da Faculdade de Formação de Professores de Nazaré da Mata/UPE: um diálogo necessário com as políticas de Formação de Professores no Brasil. 2005. 120f. Dissertação (Mestrado em Educação) - Universidade Federal de Pernambuco, Recife, 2005. Disponível em:<http://repositorio.ufpe.br/bitstream/handle /123456789/4701/arquivo5806_1.pdf?sequence $=1 \&$ isAllowed=y>. Acesso em: 29 dez. 2017.

DINIZ-PEREIRA, J. E. Formação de professores da Educação Básica no Brasil no limiar dos 20 anos da LDBEN. Notandum, Porto-PT, n.42, p. 138-160, set./dez. 2016. Disponível em:< http://www.hottopos.com/notand42/10\%20\%20JULIO\%20DINIZ.pdf>. Acesso em: 20 out. 2017.

FEDECHEM, R. A. As múltiplas dimensões no processo formativo de professores no contexto do Programa Institucional de Bolsas de Iniciação a Docência (PIBID) Subprojeto Física-UFPR (2009-2012). 2013. 126f. Dissertação (Mestrado em Educação em Ciências e em Matemática) Universidade Federal do Paraná, Curitiba, 2013. Disponível em:<http://acervodigital.ufpr.br/bitstream/handl e/1884/31871/R\%20-\%20D\%20- 
\%20ROBERTO\%20ALEXANDRE\%20FEDECHEM.pdf ?sequence=1\&isAllowed=y>. Acesso em: $29 \mathrm{dez}$. 2017.

FERREIRA DA SILVA, R. As políticas curriculares no curso de Filosofia da Universidade Federal do Maranhão: relações de poder e a regulação do currículo. 2008. 205f. Tese (Doutorado em Educação) - Universidade de São Paulo, São Paulo, 2008. Disponível em:<http://www.teses.usp.br/teses/disponiveis/ 48/48134/tde-05112009-143421/pt-br.php >.

Acesso em: 28 dez. 2017.

FERREIRA, E. A. Políticas De Formação De Professores Pós-LDB: O Programa MAGISTERCEARÁ na visão de seus gestores. 2014. 188f. Dissertação (Mestrado em Educação) - Pontifícia Universidade Católica de Minas Gerais, Belo Horizonte, 2014. Disponível em:<http://www.biblioteca.pucminas.br/teses/E ducacao_FerreiraEA_1.pdf >. Acesso em: $28 \mathrm{dez}$. 2017.

FREITAS, V. S. Políticas de formação de professores da educação básica: a experiência da Universidade Estadual De Feira De Santana - BA. 2016. Dissertação (Mestrado em Gestão de Políticas Públicas e Segurança Social) Universidade Federal do Recôncavo da Bahia, 2016.

GATTI, B. A. Formação de professores no Brasil: características e problemas. Educação \& Sociedade, Campinas, v. 31, n. 113, p. 1355-1379, out./dez. $2010 . \quad$ Disponível em:<http://www.scielo.br/scielo.php?script=sci_ arttext\&pid=S0101-73302010000400016 >.

Acesso em: 20 out. 2017.

GATTI, B. A.; BARRETO, E. S. de S.; ANDRÉ, M. E. D. A. As políticas de formação inicial de professores. In: GATTI, B. A.; BARRETO, E. S. S.; ANDRÉ, M. E. D. A. Políticas docentes no Brasil: um estado da arte. Brasília: UNESCO, 2011.

GIMENES, C. I. O Programa Institucional de Bolsa de Iniciação à Docência (PIBID) e a formação de professores de ciências naturais: possibilidade para a práxis na formação inicial? 2016. 247f. Tese (Doutorado em Educação) - Universidade de São Paulo, São Paulo, 2016. Disponível em:<http://www.teses.usp.br/teses/disponiveis/ 48/48134/tde-22122016-110603/pt-br.php>. Acesso em: 29 dez. 2017.

GOMES, D. F. Implementação de licenciaturas para a formação de professores da educação básica nos Institutos Federais de Educação, Ciência e Tecnologia. 2013.164 f. Dissertação (Mestrado em Educação) - Universidade de Brasília, Brasília, 2013. Disponível em:<http://repositorio.unb.br/bitstream/10482/ 14791/1/2013_DanielaFernandesGomes.pdf>. Acesso em: 28 dez. 2017.

GONDIM DE OLIVEIRA, K. Concepções históricas e políticas da formação de professores no Brasil: um enfoque sobre as políticas dos governos FHC e Lula. 2016. 143f. - Dissertação (Mestrado) Universidade Federal do Ceará, Programa de Pósgraduação em Educação Brasileira, Fortaleza, $2016 . \quad$ Disponível em:<http://www.repositorio.ufc.br/bitstream/riu fc/19675/1/2016_dis_kgoliveira.pdf>. Acesso em: 28 dez. 2017.

LAUANDE, M. F. R. F. Política de formação de professores: uma leitura a partir da análise do programa especial de formação de professores para a educação básica PROEB/UFMA. 2010. 308f. Tese (Doutorado em Educação) Universidade Federal do Rio Grande do Norte, Natal, 2010.2 Disponível em:<https://repositorio.ufrn.br/jspui/bitstream/ 123456789/14330/1/MariaFRFL_TESE.pdf>.

Acesso em: 28 dez. 2017.

LEAL, A. D. Itinerários de políticas de formação inicial de professores para os anos finais do ensino fundamental e médio $=$ a experiência de duas universidades estaduais paulistas. 2011. 256f. Tese (doutorado em Educação) Universidade Estadual de Campinas, Campinas, SP. Disponível em: $<$ http://www.bibliotecadigital.unicamp.br/docum ent/?code $=000845812>$. Acesso em: 20 out. 2017.

MALACHEN, J. As políticas de formação inicial a distância de professores no Brasil. 2007. 237f. Dissertação (Mestrado em Educação) Universidade Federal de Santa Catarina, Florianópolis, 2007.

MANDELI, A. de S. Fábrica de professores em nível superior: a Universidade Aberta no Brasil 
(2003-2014). 2014. 262f. Dissertação (Mestrado em Educação) - Universidade Federal de Santa Catarina, Florianópolis, 2014.

MASSON, G. Políticas de formação de professores: as influências do neopragmatismo da agenda pós-moderna. 2009. 245 f. Tese (Doutorado em Educação) - Universidade Federal de Santa Catarina, Florianópolis, 2009. Disponível em: $<$

https://repositorio.ufsc.br/bitstream/handle/123 456789/93077/274623.pdf?sequence=1\&isAllow ed=y>. Acesso em: 08 dez. 2017.

MATTIAUDA, M. L. Políticas para a Formação de Professores de língua estrangeira: o Curso de Letras do Centro Universitário-MT - UNIVAG. 2006. 90f. Dissertação (Mestrado em Educação) Universidade Católica Dom Bosco, Campo Grande, 2006. Disponível em: <http://site.ucdb.br/public/mddissertacoes/7867-politicas-para-formacao-deprofessores-de-lingua-estrangeira-o-curso-deletras-do-centro-universitario-de-varzea-grandemt-univag.pdf>. Acesso em: 28 dez. 2017.

MEDINA DA SILVA, S. Diretrizes curriculares nacionais e a formação de professores: flexibilização e autonomia. 2006. 189p. Tese (doutorado) - Universidade Estadual de Campinas, Faculdade de Educação, Campinas, SP. Disponível em: <http://libdigi.unicamp.br/document/?code=vtls 000381468>. Acesso em: 28 dez. 2017

MINDAL, C. B.; GUÉRIOS, E. C. Formação de professores em instituições públicas de ensino superior no Brasil: diversidade de problemas, impasses, dilemas e pontos de tensão. Educar em Revista, Curitiba: Editora UFPR, n. 50, p. 21-33, out./dez. 2013.2 Disponível em:<http://www.scielo.br/pdf/er/n50/n50a03.pd f>. Acesso em: 20 out. 2017.

MONTEIRO OLIVEIRA, S. Origem e organização do sistema de ensino e as políticas de formação docente no estado de Roraima. 2016. $247 \mathrm{f}$. Tese (Doutorado em Educação) - Universidade Nove de Julho, São Paulo, 2016. Disponível em:<http://bibliotecatede.uninove.br/handle/ted e/1538\#preview-link0>. Acesso em: 29 dez. 2017.

MOURA, E. J. S. Iniciação à docência como política de formação de professores. 2013. $161 \mathrm{f}$.
Dissertação (Mestrado em Educação) Universidade de Brasília, Brasília, 2013. Disponível em: $<$ http://repositorio.unb.br/bitstream/10482/150 25/1/2013_EduardoJunioSantosMoura.pdf>. Acesso em: 29 dez. 2017.

OLIVEIRA, N. N. B. M. Políticas de formação de professores no manifesto dos pioneiros e no contexto da atual reforma do ensino superior. 2006. 175 f. Dissertação (Mestrado em Educação) - Pontifícia Universidade Católica de Goiás, Goiânia, 2006. Disponível em: <http://tede2.pucgoias.edu.br:8080/bitstream/te de/1167/1/NADJA\%20NARA\%20BORGES\%20MES QUITA\%20OLIVEIRA.pdf $>$. Acesso em: $29 \mathrm{dez}$. 2017.

OLIVERI, A. M. R. Políticas de formação de professores no Brasil: um estudo sobre o PIBID na região dos Inconfidentes - MG. 2014. 161 f. Dissertação (Mestrado em Educação) Universidade Federal de Ouro Preto, Instituto de Ciências Humanas e Sociais, Mariana, 2014. Disponível em: <http://www.repositorio.ufop.br/bitstream/1234 56789/3941/1/DISSERTA\%c3\%87\%c3\%830_Pol\% c3\%adticasForma\%c3\%a7\%c3\%a3oProfessores.p df>. Acesso em: 29 dez. 2017.

O'REILLY, M. C. R. B. Projeto Veredas: a experiência de formação a distância, proposta pelo governo de Minas Gerais como parte das políticas atuais para a formação de professores no Brasil. 2005. 225 f. Dissertação (mestrado) Universidade Estadual Paulista, Instituto de Biociências, 2005. Disponível em:

<https://repositorio.unesp.br/bitstream/handle/ 11449/90160/oreilly_mcrb_me_rcla.pdf?sequenc $\mathrm{e}=1 \&$ isAllowed $=\mathrm{y}>$. Acesso em: 08 dez. 2017.

ROCHA, S. R. P. Projeto Veredas: um sonho realizado pelas Professoras do Alto Vale do Jequitinhonha. 2006. 151f. Dissertação (Mestrado em Educação) - Pontifícia Universidade Católica de Minas Gerais, Belo Horizonte, 2011. Disponível em: $<$ http://server05.pucminas.br/teses/Educaca o_RochaSR_1.pdf>. Acesso em: 28 dez. 2017.

RODRIGUES, L. C. M. Programas federais de formação inicial de professores da educação básica no Brasil: maquinaria de uma governamentalidade. 2016. 162 f. Dissertação (Mestrado em Educação) - Instituto de Ciências 
Humanas e Sociais, Universidade Federal de Ouro Preto, Mariana, 2016. Disponível em:<http://www.repositorio.ufop.br/handle/123 456789/6476>. Acesso em: 28 dez. 2017.

ROMANOWSKI, J. P. Formação inicial de professores: implicações com a educação básica. In: CONGRESSO NACIONAL DE EDUCAÇÃO (EDUCERE); SEMINÁRIO INTERNACIONAL DE REPRESENTAÇÕES SOCIAIS, SUBJETIVIDADE E EDUCAÇÃO (SIRSSE), 10, 1, 2011, Curitiba. Anais... Curitiba: PUC/PR, 2011. p. 14895-14909. Disponível em: <http://educere.bruc.com.br/CD2011/pdf/5198_ 2844.pdf>. Acesso em: 19 out. 2017.

SEMESP. Assessoria Econômica. Mapa do Ensino Superior. 5. ed., 2015. Disponível em:< http://convergenciacom.net/pdf/mapa-ensinosuperior-brasil-2015.pdf >. Acesso em: 12 out. 2017.

SILVA NETO, N. C. A Capes e a política nacional de formação de professores da educação básica no Brasil. 2017. 99f. Dissertação (Mestrado em Educação) - Universidade Estadual Paulista, Marília, $2017 . \quad$ Disponível em:<https://repositorio.unesp.br/bitstream/han dle/11449/149990/silvaneto_nc_me_mar.pdf?se quence=3\&isAllowed=y $>$. Acesso em: $29 \mathrm{dez}$. 2017.

SILVA, J. S. Política De Formação De Professores: reforma e mudança em um curso de licenciatura em Ciências Biológicas. 2014. 130f. Dissertação (Mestrado em Educação Científica e Formação de Professores) - Universidade Estadual do Sudoeste da Bahia, Jequié/BA, 2014. Disponível em: $<$ https://sucupira.capes.gov.br/sucupira/public/c onsultas/coleta/trabalhoConclusao/viewTrabalho Conclusao.jsf?popup=true\&id_trabalho $=1329268$ \#>. Acesso em: 08 dez. 2017.

SILVA, L. B. A política de formação inicial de professores e a implementação do componente curricular Prática Profissional na Licenciatura de Geografia do CEFET-RN. 2006. 209 f. Dissertação (Mestrado em Educação) - Universidade Federal do Rio Grande do Norte, Natal, 2006.

SILVA, S. M. O Programa Institucional de Bolsa de Iniciação à Docência como uma política pública de formação de professores: aprendentes e aprendizagens do processo formativo. 2016. 133f. Dissertação (Mestrado em Educação) - Universidade Estadual do Sudoeste da Bahia, Vitória da Conquista, 2016. Disponível em:<http://www2.uesb.br/ppg/ppged/wpcontent/uploads/2016/10/SOLANGE-MENDESDA-SILVA.pdf>. Acesso em: 29 dez. 2017.

SOUZA, J. R. M. A. Projeto Construindo Saberes e a formação para o exercício da docência: avaliação do Programa Prodocência no âmbito da Universidade Federal do Tocantins 2011. 128 f. Dissertação (Mestrado em Avaliação de Políticas Públicas) - Universidade Federal do Ceará, Pro Reitoria de Pesquisa e Pós-Graduação, Programa de Pós-Graduação em Avaliação de Políticas Públicas, Fortaleza, 2011. Disponível em:< http://www.repositorio.ufc.br/bitstream/riufc/23 72/1/2011_Dis_JacquelineRMASOUZAl.pdf >. Acesso em: 29 dez. 2017.

SUSIN, A. S. O Plano Nacional de Formação De Professores da Educação Básica no contexto das políticas de formação inicial: pressupostos, contrapontos e desafios a partir de uma experiência em andamento. 2015. 107f. Dissertação (Mestrado em Educação) Universidade do Oeste de Santa Catarina, Joaçaba, 2015. Disponível em:< https://sucupira.capes.gov.br/sucupira/public/co nsultas/coleta/trabalhoConclusao/viewTrabalhoC onclusao.jsf?popup=true\&id_trabalho $=2810066 \#$ >. Acesso em: 08 dez. 2017.

TANJI, T. O que você precisa saber sobre a PósGraduação no Brasil. Revista Galileu, 2017. Disponível em: <http://revistagalileu.globo.com/Revista/noticia/ 2017/08/o-que-voce-precisa-saber-sobre-posgraduacao-no-brasil.html>. Acesso em: 04 jan. 2018.

VEDOVATTO, J. Formação de professores de Arte: do currículo mínimo às Diretrizes Curriculares Nacionais para a graduação em Artes Visuais. 2010. 82f. Dissertação (Mestrado em Educação) - Universidade do Oeste de Santa Catarina, Joaçaba, 2010. Disponível em:<http://www.unoesc.edu.br/images/uploads/ mestrado/Jusciane_Vedovatto.pdf $>$. Acesso em: 28 dez. 2017.

VIANA, M. H. M. Programa Magister Ceará: reflexões sobre formação docente. 2011. 177 f. Dissertação (Mestrado em Avaliação de Políticas 
Públicas) - Universidade Federal do Ceará, Pro Reitoria de Pesquisa e Pós-Graduação, Programa de Pós-Graduação em Avaliação de Políticas Públicas, Fortaleza, 2011. Disponível em:<http://www.repositorio.ufc.br/bitstream/riu fc/2328/1/2011_Dis_MHosanaMVIANA.pdf >.

Acesso em: 28 dez. 2017.

Recebido para publicação em: 03/11/2017

Revisado em: 30/01/2018

Aceito em: 09/03/2018 